\title{
Creation of nanostructures to study the topographical dependency of protein adsorption
}

\author{
C. Galli ${ }^{\text {a,*, M. Collaud Coen }}{ }^{\text {a }}$, R. Hauert ${ }^{\text {b }}$, V.L. Katanaev ${ }^{\mathrm{c}}$, P. Gröning ${ }^{\mathrm{a}}$, \\ L. Schlapbach ${ }^{a}$
}

${ }^{a}$ Solid State Physics Research Group, University of Fribourg, Pérolles, CH-1700 Fribourg, Switzerland

${ }^{\mathrm{b}}$ Swiss Federal Laboratories for Material Testing and Research (EMPA), Überlandstrasse 129, CH-8600 Dübendorf, Switzerland

${ }^{\mathrm{c}}$ Institute of Biochemistry, University of Fribourg, Pérolles, CH-1700 Fribourg, Switzerland

Received 25 September 2001; received in revised form 30 October 2001; accepted 7 January 2002

\begin{abstract}
Nanostructures of sizes comparable to protein dimensions are created on $\mathrm{Si}$ and $\mathrm{Ti}$ surfaces by local anodic oxidation (LAO) using the atomic force microscope (AFM). The characterization of the surface by X-ray photoelectron spectroscopy (XPS) reveals that this method assures a modification of the topography of the surface without a change of its chemical composition. Surfaces structured by LAO therefore represent ideal systems to study the dependence of protein adsorption on topography. We are able to visualize the created nanostructures with an AFM and successively adsorb the proteins in situ, rinse and image the new surface. The densities of adsorbed proteins on the nanostructured and neat surfaces are compared and we find that the protein arrangement depends on the underlying nanostructures, showing that proteins can "sense" the topography of surfaces at the nanometer scale. This result can be considered as the nanoscale analogous of the adsorption found for cell systems on micrometer structures. (c) 2002 Elsevier Science B.V. All rights reserved.
\end{abstract}

Keywords: Nanostructures; Topography; Protein; Adsorption; Surface

\section{Introduction}

The biocompatibility of materials in implant or biosensor fields strongly depends on first interactions occurring between a given surface and a biological environment. It is possible to influence

\footnotetext{
* Corresponding author. Tel.: + 41-26-300-9076; fax: + 4126-300-9747.

E-mail address: carine.galli@unifr.ch (C. Galli).
}

these interactions by modifying the surface properties, which are the chemistry, the surface charge and the topography of the surface. In this paper, we are especially interested in the only role of the topography. A number of studies have shown that cells 'sense' the topography at the $\mu \mathrm{m}$ scale, growing along grooves of determined width and depth [1-5]. Nevertheless proteins are always present on surfaces, forming an interface layer, on which further proteins or cells will adsorb, because protein adsorption is the first phenomenon which takes place when a foreign material is brought 
into contact with biological environment. Therefore we focus our study in the role of topography on protein adsorption, which has never been addressed as only parameter. Created structures have to be scaled down to reach sizes accordingly to proteins, i.e. in the $\mathrm{nm}$ range, which is smaller than the lithography resolution. The scanning probe microscopy (SPM) permits manipulation of molecules, measuring surfaces at the atomic scale or modifying the surface at the $\mathrm{nm}$ scale. Therefore an AFM is used to create nanostructures applying the LAO, which allows us to change the topography without modifying the surface chemistry.

The topographical dependency of actin adsorption on $\mathrm{Ti}$ has already been published elsewhere [6]. As a complement, we describe here the method used for the nanostructure creation, and present the dependence of different parameters as well as the chemical composition analysis of the nanostructured surfaces. As application of the method, we describe the adsorption of different protein systems, which allows us to study the biological activity of adsorbed proteins as well as the orientation of adsorbed proteins on nanostructures. Comparison of the actin adsorption on $\mathrm{Ti}$ and $\mathrm{Si}$ shows that the amount of adsorbed filaments is higher on Si.

\section{Materials and methods}

\subsection{Proteins}

For this study, three different proteins have been used: two standard proteins for immunology tests (protein $\mathrm{A}$ and $\mathrm{IgG}$ ) and F-actin, which forms filaments and is active in the cell motion and muscular contraction. Proteins A (soluble extracellular from Staphylococcus aureus, Fluka, Buchs, Switzerland) are globular proteins of $44.2 \mathrm{kDa}$. They have an average diameter of $3 \mathrm{~nm}$ [7] and their isoelectrical point is $\mathrm{pI}=5.1$ [8]. We diluted them in nanodeionized water, which has been stocked under air conditions, so that due to the $\mathrm{CO}_{2}$ absorption, the water $\mathrm{pH}$ was comprised between 5 and 6 , near the $\mathrm{pI}$ of protein A. The concentration was 2.4 $\mu \mathrm{M}$. The IgG antibodies (Fluka, Buchs, Switzerland) have a $\mathrm{Y}$ shape measuring $13.7 \mathrm{~nm}$ in width at their extreme and $10.4 \mathrm{~nm}$ in height [9]. Their weight is $150 \mathrm{kDa}$ and they can bind specifically on protein A by their Fc domain. We also diluted them in nanodeionized water, at a concentration of $1 \mu \mathrm{M}$.

F-actin is built up from actin monomers of 42 $\mathrm{kDa}$ and forms filaments having a width of $6.5-$ $8.2 \mathrm{~nm}$ [10]. Their isoelectrical point ranges from 5.06 to 5.27 [11], and is thus similar to protein A. Rabbit muscle F-actin was prepared as described in [12] and its purity has been controlled by PAGE. We get only one line, which means that our actin solution contained no impurities. A F-actin concentration of $6.65 \mu \mathrm{M}$ was determined by rhodamine phalloidin fluorescence enhancement [13].

For all the protein adsorptions, we placed a droplet of protein solution on the sample during different times, and rinsed the surface with a micropipette by a number of sucking-rinsing processes using nanodeionized water, so that non-adsorbed proteins or non-specifically bounded IgG were washed out.

\subsection{Substrates}

In order to measure proteins of some nanometers with the AFM, we need extremely flat substrates. Native silicon $\mathrm{Si}\langle 111\rangle$ meets this condition having a natural root mean square (RMS)-roughness of $0.2 \mathrm{~nm}$ over $10 \mu \mathrm{m}^{2}$. To study the protein adsorption on Ti surface that is known to be biocompatible [14,15], we also evaporated a $10 \mathrm{~nm}$ thick titanium layer on $\mathrm{Si}$ at a speed of $50 \AA / \mathrm{s}$. The RMS-roughness of this Ti layer is $0.35 \mathrm{~nm}$ for $10 \mu \mathrm{m}^{2}$ surfaces.

\subsection{The atomic force microscope (AFM)}

The creation of the nanostructures, the imaging of the new surface topography and the adsorbed proteins were performed by an AFM (NanoScope III from Digital Instruments Inc, Santa Barbara, USA). The nanostructures were 
created in ambient air in Contact Mode (CM) with Si CM-tip (448 $\mu \mathrm{m}$-long cantilever and $0.1-$ $0.31 \mathrm{Nm}^{-1}$ force constant) or TappingMode ${ }^{\mathrm{TM}}$ tip (127 $\mu \mathrm{m}$-long cantilever and 53-88 $\mathrm{Nm}^{-1}$ force constant). All the AFM images are measured in air in TM if not otherwise specified. Because proteins are soft materials, the applied force is minimized so as not to deform them [16]. All AFM images shown are original unprocessed and unfiltered data. The room temperature is 23 ${ }^{\circ} \mathrm{C}$ and the relative humidity is about $30 \%$.

\subsection{The X-ray photoelectron spectroscopy (XPS)}

We measure the $\mathrm{Si}\langle 111\rangle$ native surface and a $100 \mu \mathrm{m}$ square of nanostructured Si with a Quantum 2000 XPS from PHI with $10 \mu \mathrm{m}$ lateral resolution. The radiation was monochromatized $\mathrm{Al} \mathrm{K} \alpha(1486.6 \mathrm{eV})$ and the $\mathrm{X}$-ray source was operated at $4.9 \mathrm{~W}$. In order to focus the measurement on or outer the nanostructures, a scanning X-ray image (SXI) has been performed, which showed a well contrasted square of nanostructures on the secondary electron image. The surface composition was calculated from the integral corrected with the atomic sensitivity factor of the $\mathrm{O} 1 \mathrm{~s}, \mathrm{C} 1 \mathrm{~s}$ and $\mathrm{Si} 2 \mathrm{p}$ ( $\mathrm{Si}$ and $\mathrm{SiO}_{2}$ compounds) peaks after a Shirley background subtraction. We measured with a $20 \mu \mathrm{m}$ large X-ray spot at the angles of $0,30,45$ and $55^{\circ}$ reported from the normal of the surface in order to determine the oxide layer thickness $d$. The intensities of the $\mathrm{Si}$ and $\mathrm{Si}^{4+}$ signals are

$I_{\mathrm{Si}}=\mathrm{e}^{-\frac{d}{\Lambda_{\mathrm{Si}}{ }_{\text {oxide }} \cos \theta}} \int_{d}^{\infty} \sigma_{\mathrm{Si}} \operatorname{Tn}_{\mathrm{Si}} \mathrm{e}^{-\frac{z-d}{\Lambda_{\mathrm{Si}} \cos \theta}} \mathrm{d} z$ $d z I_{\mathrm{Si}_{\text {oxide }}}=\int_{0}^{d} \sigma_{\mathrm{Si}_{\text {oxide }}} T_{\text {Si }_{\text {oxide }}} \mathrm{e}^{-\frac{z}{A_{\mathrm{Si}_{\text {oxide }}} \cos \theta} d z}$

where $\Lambda$ is the mean free path of the Si2p photoelectrons, which is $23 \AA$ in Si [17] and $34.9 \AA$ in $\mathrm{Si}^{4+}$ [17]. $\sigma$ is the photoionization cross section for the Si2p level electron, which is assumed to be equal $[18,19]$ for the bulk and for the oxide layer. $T$ is the analyzer transmission function that we assume equal for all signals and $\theta$ is the angle between the normal of the surface and the photoelectron direction. $n$ is the atomic density, which can be easily obtained from $n=\rho / M$, where $\rho$ is the density $\left(2.33 \mathrm{~g} / \mathrm{cm}^{3}\right.$ for $\mathrm{SiO}_{2}$ and $2.66 \mathrm{~g} / \mathrm{cm}^{3}$ for $\mathrm{Si}$ ) and $M$ is the molecular weight (28.1 $\mathrm{g}$ for $\mathrm{Si}$ and $60.1 \mathrm{~g}$ for $\mathrm{SiO}_{2}$ ).

For the different measured angles, the oxide thickness is given by the ratio of the intensities of the $\mathrm{Si}$ signal over the $\mathrm{Si}^{4+}$ signal, which is finally

$d=\Lambda_{\mathrm{Si}_{\text {oxide }}} \cos \theta \ln \left(1+\frac{I_{\mathrm{Si}_{\text {oxide }}} n_{\mathrm{Si}} \Lambda_{\mathrm{Si}}}{\left.I_{\mathrm{Si}_{\mathrm{Si}} n_{\mathrm{Si}_{\text {oxide }}} \Lambda_{\mathrm{Si}_{\text {oxide }}}}\right)}\right.$

\section{Results and discussion}

\subsection{Creation and characterization of nanostructures}

\subsubsection{The local anodic oxidation (LAO)}

We use the LAO method, which has been developed in the semiconductor research domain $[20,21]$ to create defined nanopattern on $\mathrm{Si}$ or $\mathrm{Ti}$ surfaces. In LAO, advantage is taken of the fact that the sample is covered by a thin water film, due to the humidity of the air (see Fig. 1). By applying a voltage between the AFM-tip and the
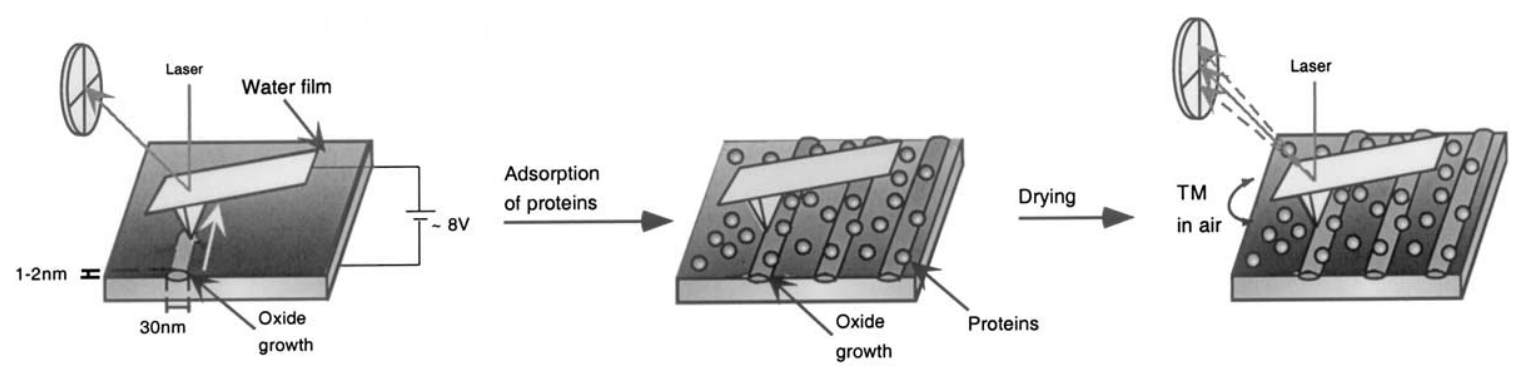

Fig. 1. The LAO allows us to create nanostructures by applying a voltage between the AFM-tip and the sample. We adsorb proteins on the new topography, dry the sample and image by AFM the adsorbed proteins in TM. 


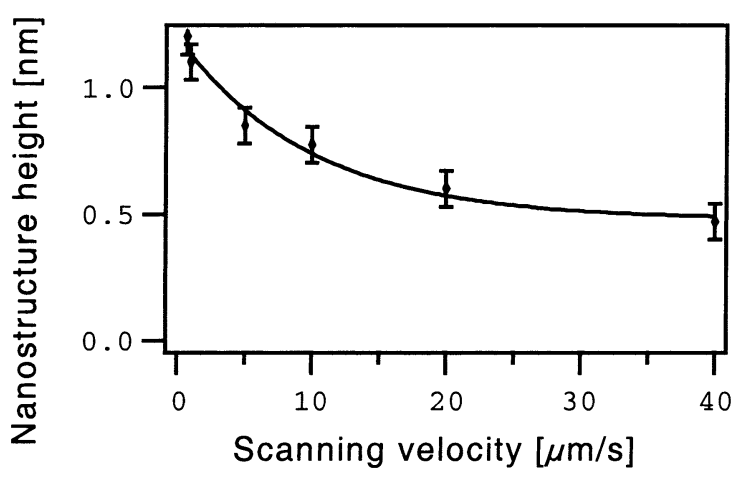

Fig. 2. Nanostructure height as a function of the scanning tip velocity. The applied voltage between the tip and the sample is $8 \mathrm{~V}$.

sample surface, the water molecules dissociate locally [21,22], and $\mathrm{OH}^{-}$ions adsorb subsequently onto the surface. Due to the larger lattice constant of oxide compared to the metal lattice constant, a thickening of the native oxide layer by LAO induces the creation of nanostructures above the surface. The formation of the nanostructures depends typically on the substrate, the degree of relative humidity $[23,24]$, the tip shape [25], the distance between the tip and the sample [26], the tip velocity (see Fig. 2) and the applied voltage (see Fig. 3).

We explore the effect of scanning velocity on the creation of nanostructures and find that the height of the nanostructures systematically decreases as the scanning velocity is increased. In

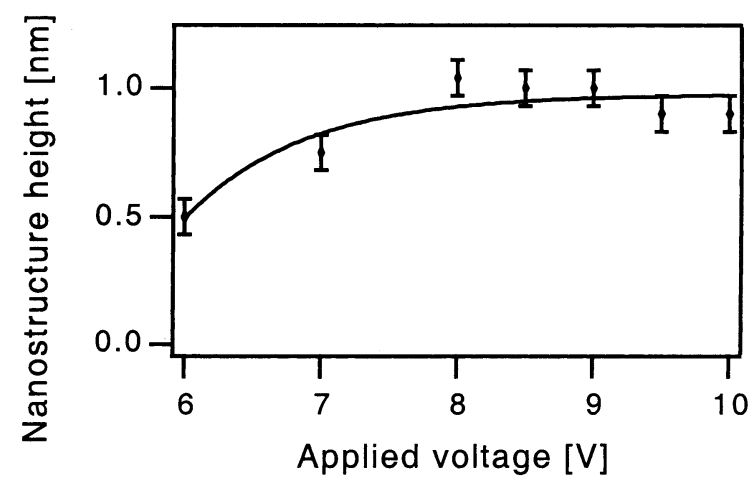

Fig. 3. Nanostructure height as a function of the voltage applied between the AFM-tip and the sample for a tip velocity of $1 \mu \mathrm{m} / \mathrm{s}$.
Fig. 2 the result of a set of structuring scans are shown, where the same CM-tip has been used. The applied voltage between the tip and the sample was $8 \mathrm{~V}$ and the distance between the tip and the sample was kept constant. All images in this section were measured in CM. The nanostructure height decreases continuously with increasing scanning velocities, to reach $0.5 \mathrm{~nm}$ for a tip velocity of $40 \mu \mathrm{m} / \mathrm{s}$. The highest homogeneous nanostructures are obtained with a scanning velocity of $0.7 \mu \mathrm{m} / \mathrm{s}$ and have a size of $1.2 \mathrm{~nm}$. At lower tip velocities the water film between the AFM-tip and surface tends to disrupt, such that the nanostructures present interruptions. We determine the limit in velocity, below which the formation of nanostructures cannot be well controlled for our setup to be $1 \mu \mathrm{m} / \mathrm{s}$ for an applied voltage of $8 \mathrm{~V}$.

The height of the nanostructures depends not only on the scanning velocity but also on the applied voltage. In Fig. 3 we show the results of a set of experiments, where again the same CM-tip was used and the tip-sample distance was kept constant. The tip velocity was chosen to be $1 \mu \mathrm{m} / \mathrm{s}$ to ensure the creation of homogeneous structures. The height of the nanostructures drastically increases for voltages between 6 and $8 \mathrm{~V}$, and then remains constant at a maximal value of $1 \mathrm{~nm}$ for higher voltages.

The full width at half maximum (FWHM) is found to be independent of the scan velocity and the applied voltage. For the two sets of experiments shown in Figs. 2 and 3 we determine a FWHM of $100 \mathrm{~nm}$. However, we are able to vary the FWHM by varying the tip shape and the tip-sample distance. We have been able to create structures with FWHM of $20 \mathrm{~nm}$, which is to our knowledge the best lateral resolution which can be achieved [23,25,27].

LAO not only enables us to control the height and width of nanostructures, figures of any shape can also be created by programming the path of the tip over the sample surface. Two examples are shown in Fig. 4a and b. The two first letters of our university city FR and the wire netting structure are created in CM with a CM-tip at the optimal applied voltage of $8 \mathrm{~V}$ and a tip velocity of $1 \mu \mathrm{m} \mathrm{s}^{-1}$. The wire netting structure is made in 


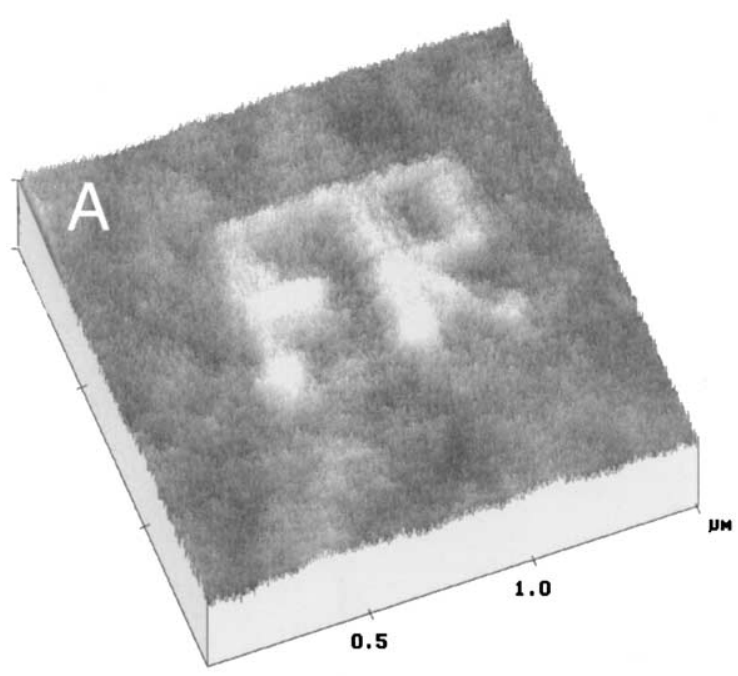

In ambient air native oxidation takes place and the native oxidation process will differ from one material to another. This difference affects the oxidation by LAO, such that the creation of nanostructures will differ depending on the material used. For silicon the oxide layer grows slowly and reaches a defined maximal thickness after a couple of days [28]. As a result of that the $\mathrm{Si}$ nanostructures obtained by LAO present a maximal thickness, which is the limit through which the $\mathrm{OH}^{-}$ions can diffuse. The creation of $\mathrm{Si}$ nanostructures presents no particular difficulties.

In contrast Ti oxide is formed spontaneously in a fraction of a second [29] after exposure to air and grows continuously [30]. Creation of nanostructures on $\mathrm{Ti}$ presents different difficulties in ambient air. The tip-sample distance is a very sensitive parameter. Simply due to the non-linear curvature of the piezoelectrical part of the AFM, which is used to move the sample, nanostructures of different heights are obtained. Also the creation of nanostructures with our voltage setup limit of $12 \mathrm{~V}$ becomes impossible to achieve if the native oxide layer is too thick.

\subsubsection{Characterization of the nanostructured surfaces by $X$-ray photoelectron spectroscopy (XPS)}

XPS is a standard method used to analyze the chemical composition of a surface. By illuminating the surface with X-rays, electrons of the different surface elements will be excited and leave the surface. They are collected and counted in regard to their kinetic energy, which is specific for each photoelectron coming from a defined shell of an element. XPS measurements of both native and nanostructured $\mathrm{Si}\langle 111\rangle$ reveals the presence of silicon, oxygen and contaminations of carbon. Fig. 5 shows $\mathrm{Si} 2 \mathrm{p}$ peaks measured on the native $\mathrm{Si}$ surface (Fig. 5a) and on the nanostructured $\mathrm{Si}$ surface (Fig. 5b), where the $\mathrm{Si} 2 \mathrm{p}_{3 / 2}$ peaks are normalized. The Si2p core level ( $\mathrm{Si}$ ) from the bulk is found at a binding energy of $99.5 \mathrm{eV}$ and the $\mathrm{Si} 2 \mathrm{p}$ from the $\mathrm{SiO}_{2}$ layer $\left(\mathrm{Si}^{4+}\right)$ at a binding energy of $103.3 \mathrm{eV}$. All the spectra measured on nanostructured and neat $\mathrm{Si}$ present exactly the same shape with peaks at the same binding energies. Therefore we can affirm that the nanostruc$\mathrm{V}$, the LAO permits an increase of the oxide thickness up to a maximal limit of $2 \mathrm{~nm}$ on $\mathrm{Si}$.

two steps: in a first scan parallel lines are created, and in a second scan the lines perpendicularly to the first one are produced. The simple lines have a height of $0.8 \mathrm{~nm}$ but the height at the intersections is nearly $50 \%$ higher. Scanning once more over the intersection areas does not lead to further growth. It seems that for an applied voltage of 8 
tures present exactly the same chemistry as neat $\mathrm{Si}$, and that the LAO treatment does not change the surface chemistry. The topography is therefore the only modified surface parameter for protein adsorption.

XPS measurements also allow us to determine the oxide thickness present before and after LAO treatments due to the fact that the mean free path of an electron depends on its kinetic energy and is therefore constant for a defined photoelectron. By varying the analysis angle reported from the normal of the surface it is possible to analyze the chemical composition at a different depth from the surface. If the metallic $\mathrm{Si}$ signal is always
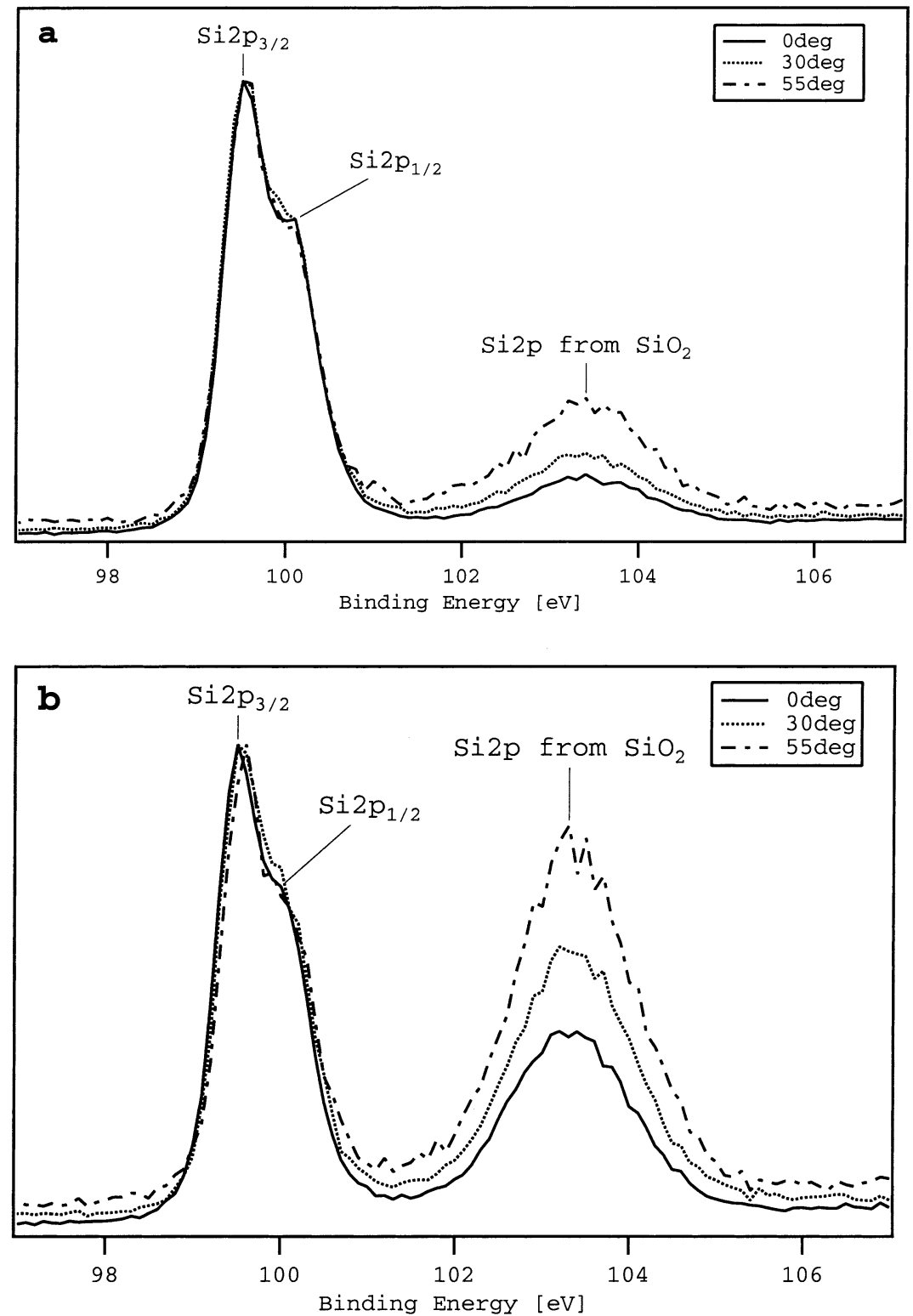

Fig. 5. XPS measurement of (a) the native Si surface and (b) the nanostructured Si surface. The Si2 $\mathrm{p}_{3 / 2}$ peaks are normalized in both figures. 
dominant, a greater amount of $\mathrm{Si}^{4+}$ is present on nanostructures (Fig. 5b). No $\mathrm{Si}^{x+}(x \leq 3)$ peak of binding energy comprised between 100.5 and 102 $\mathrm{eV}$ [31] is measured on native $\mathrm{Si}$ and on the nanostructured $\mathrm{Si}$. This result demonstrates that the interface between the $\mathrm{SiO}_{2}$ and the bulk is abrupt and remains essentially unchanged after LAO treatments. The mean value of the oxide layer thickness calculated for the different angles gives $6.9 \pm 1 \AA$ for the native oxide and $20.3 \pm 1$ $\AA$ for the nanostructures. The difference of $13.4 \AA$ represents the created oxide thickness due to the LAO treatment, which is in agreement to the height difference measured with the AFM. The created oxide thickness corresponds to the growth of six added monolayers, considering that the thickness of one monolayer of silicon oxide is 2.2 $\AA$ [32]. This suggests that the oxide growth due to the LAO follows the same layer-by-layer growth as $\mathrm{Si}$ in air at room temperature [32,33].

XPS measurements on Ti show that the composition of the created nanostructures is pure $\mathrm{TiO}_{2}$. Because no metallic Ti signal is measured we can deduce that the native oxide layer is thicker than $2-3 \mathrm{~nm}$.

On $\mathrm{Si}$ and on $\mathrm{Ti}$, the native oxide thicknesses are thick enough to assume no differences in static surface charges between the lower and the upper parts of the topographical structures, which could induce a preferential protein adsorption due to changes in electrostatic interactions.

\subsection{Protein adsorption on nanostructures}

In order to be able to study protein adsorption on the nanostructures, we developed techniques which enable us to treat the surfaces in situ, by means without removing the sample from its location in the AFM. This is necessary, as it is nearly impossible to find the very small nanostructured area once the sample has been removed from its original location. After creation and characterization of a nanostructured surface, proteins are adsorbed during a defined amount of time and the surface is subsequently rinsed and dried. This procedure ensures a defined adsorption step and possible problems of desorption-readsorption processes during the imaging are avoided [34], as well as the difficulty to image in different buffer solutions. AFM measurements are therefore performed in air. In order to be able to compare images it is important to keep the tip convolution artefact constant. We thus always use the same AFM-tip and measure in the same mode (TM in our case) for a given set of experiments.

We explore the adsorption of two proteins on nanostructured surfaces, where the nanostructures consist of parallel lines, and the two proteins differ in shape and size: protein $\mathrm{A}$ is a globular protein with a diameter of $3 \mathrm{~nm}$; F-actin forms filaments with a cross-sectional diameter of 6.5$8.2 \mathrm{~nm}$. For the globular protein A, we additionally test for its biological activity after adsorption, by adsorbing in a second step IgG antibodies.

A Si nanostructured surface is shown in Fig. 6a. The lines have a FWHM of $30 \mathrm{~nm}$ and the spacing between them is not always regular. The corresponding height histogram (Fig. 6b) can be fitted by two Gaussian curves. The first one corresponds to the neat Si surface and the second one to created lines. We determine from the peak-topeak distance the mean height of the nanostructures, which corresponds with $1.1 \mathrm{~nm}$ to roughly a third of the diameter of protein A in solution.

Shown in Fig. 7a is the surface obtained after $45 \mathrm{~s}$ adsorption of protein $\mathrm{A}$ on the nanostructured surface shown in Fig. 6a. The lines are covered by protein A but their shape remains visible despite the large amount of adsorbed protein A on the sample surface. The histogram comprises two peaks. The first peak corresponds to the protein A adsorbed on the neat surface. It is wide owing to the presence of holes in the protein layer. The second peak corresponds to the protein adsorbed on top of the created lines. This peak is much smaller, because due to the globular shape of the proteins only a few points on top of the proteins are depicted as maximum height. The peak-to-peak distance remains essentially unchanged compared to the one obtained for the surface before protein adsorption (see Fig. 6b). Profiles (not shown) on nanostructured and neat Si reveal that the height of the protein layer is in both cases of the order of $1 \mathrm{~nm}$, which corresponds to the first monolayer of adsorbed protein A on $\mathrm{Si}$ [35]. Furthermore we find that the RMS 

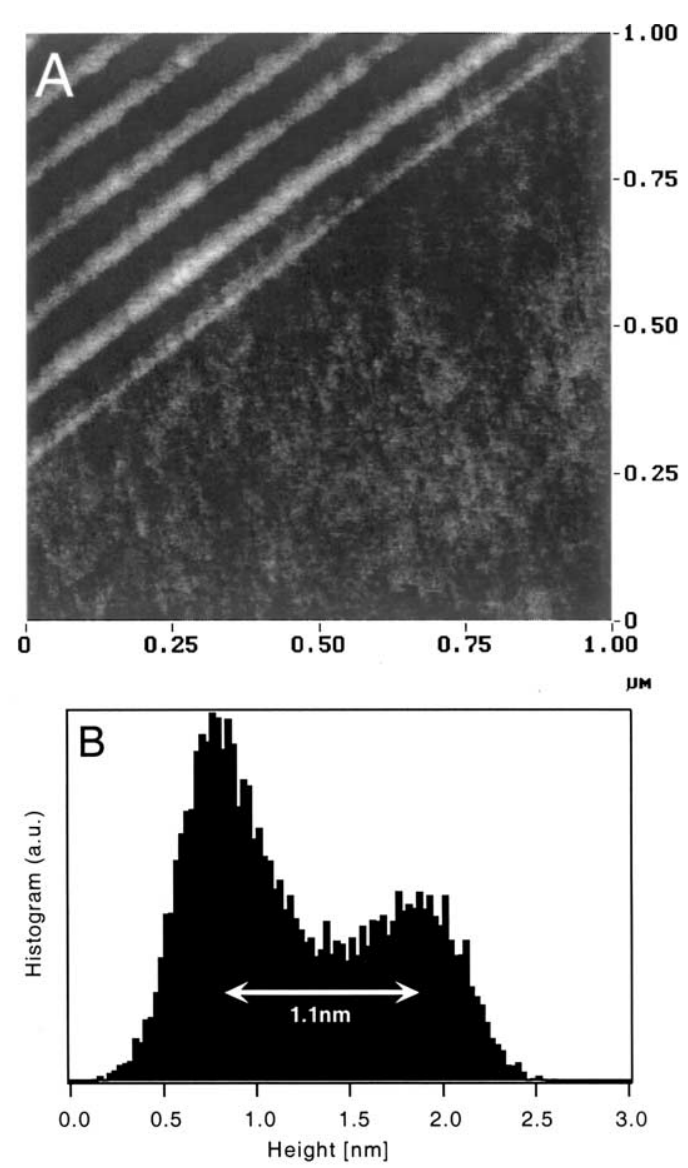

Fig. 6. AFM image (a) and height histogram (b) of nanostructured $\mathrm{Si}$. The vertical scale is $5 \mathrm{~nm}$.

roughness is identical on nanostructured and neat $\mathrm{Si}$. Clearly, there are no differences in adsorption behavior of protein A on nanostructured or neat Si.

We test for potential differences in the biological activity of the adsorbed protein A on nanostructures, by proceeding to a second adsorption step, where IgG are adsorbed during $45 \mathrm{~s}$ (Fig. 8) on the previous adsorbed protein A. The nanostructure shape remains visible, but one line with IgG corresponds to two lines with protein A due to the larger size of $\operatorname{IgG}(13.7 \mathrm{~nm})$. Different histograms on and around the nanostructured areas have been calculated. The histogram on the nanostructures is wider due to the larger roughness of the surface and the incomplete coverage by the protein layer. The decreasing part of this curve is shifted by $1.1 \mathrm{~nm}$ compared to the histogram obtained for the neat $\mathrm{Si}$, which corresponds to the nanostructure height. The nanostructure histogram is peaked around 4.7 $\mathrm{nm}$, which is much lower than the height expected for a specific binding of IgG to protein A (13.4 $\mathrm{nm})$. Clearly, the IgG is not in a standing position, independent of the underlying structure. The adsorbed protein A layer (Fig. 7) contains holes and no site blocking proteins have been adsorbed after the protein A deposition. It has been shown that the protein $\mathrm{A}$ of the first monolayer adsorbed on $\mathrm{Si}$ is $1 \mathrm{~nm}$ high and biologically non-active [35]. Therefore $\operatorname{IgG}$ can adsorb non-specifically

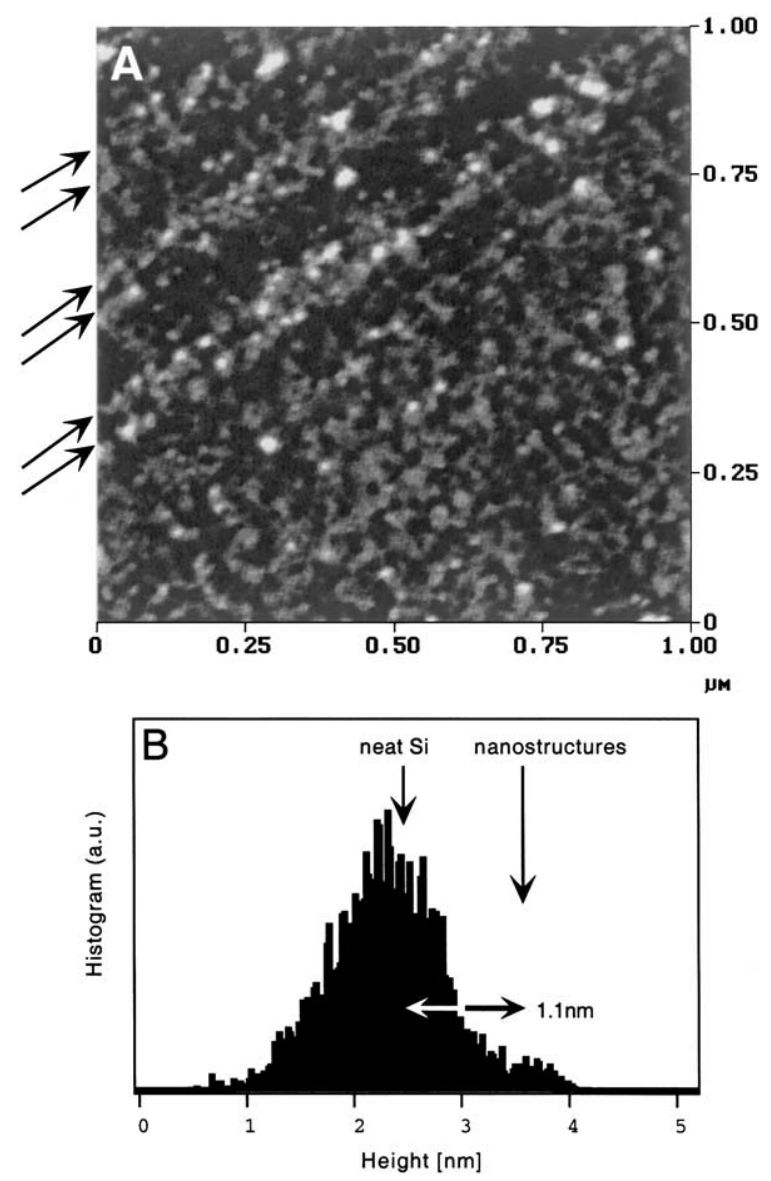

Fig. 7. AFM image (a) and height histogram (b) of protein A adsorption on the previous $\mathrm{Si}$ nanostructures. The vertical scale is $5 \mathrm{~nm}$. 

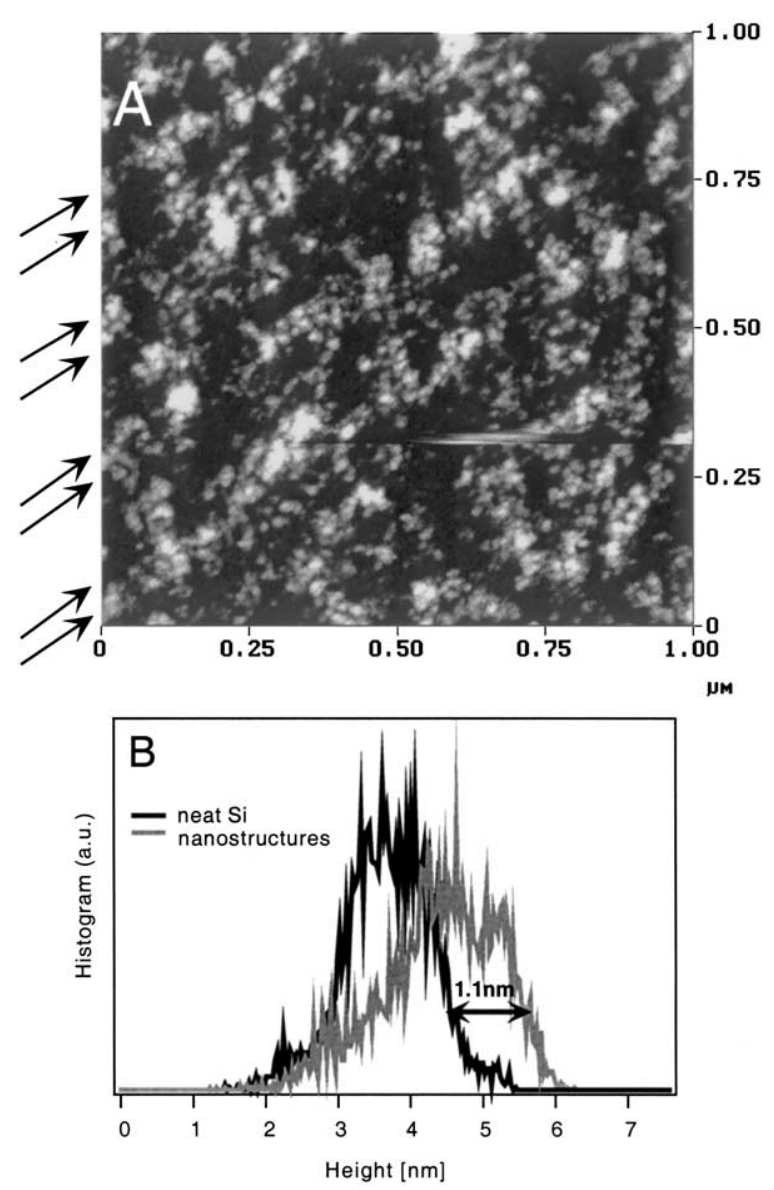

Fig. 8. (a) AFM image of $\operatorname{IgG}$ adsorbed on the preadsorbed protein A. The vertical scale is $5 \mathrm{~nm}$. (b) Height histograms on neat $\mathrm{Si}$ and on nanostructures.

between the protein $\mathrm{A}$ on neat $\mathrm{Si}$ as on nanostructures, and no preferential adsorption is noted on nanostructures.

Similar Si nanostructures have been used to adsorb filamentous proteins, in order to measure a possible orientation specificity of adsorbed proteins in contact with nanostructures. The $5 \mathrm{~s}$ F-actin adsorption is shown in Fig. 9a. F-actin covers the neat $\mathrm{Si}$ and the nanostructures are still visible due to a low protein density. Fig. $9 \mathrm{~b}$ is a magnification of the F-actin adsorbed on the nanostructures. The adsorbed filaments are forming a kind of neuronal network composed of large intersection areas, which are interconnected by different filament bundles. Even if $\mathrm{F}$-actin adsorbs
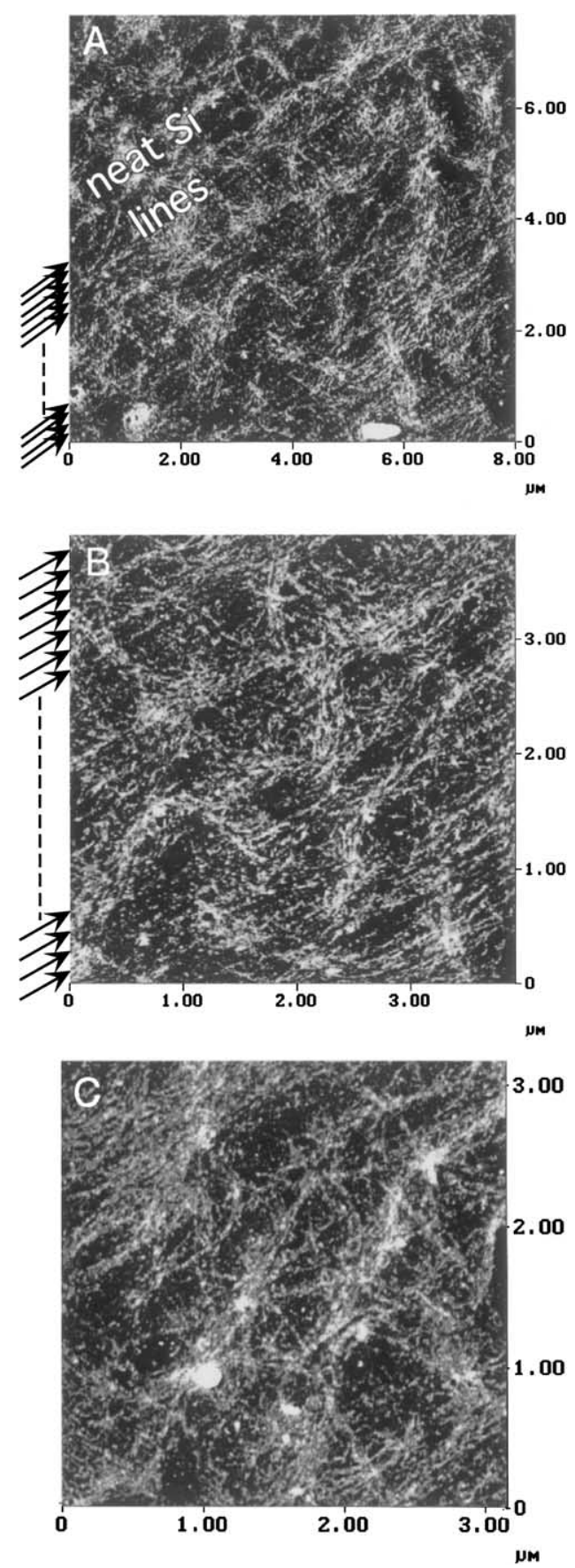

Fig. 9. Adsorption of F-actin on and outer Si nanostructures. The vertical scales are $10 \mathrm{~nm}$. (a) General view of the adsorbed F-actin. (b) Enlargement of the nanostructure area. (c) Enlargement of the neat $\mathrm{Si}$ area. 
in different directions, a preferential orientation along the nanostructures is visible. F-actin filaments are actually present in a cone of $18^{\circ}$ towards the lines. For angles between 18 and $55^{\circ}$, no filaments are present. Therefore it seems that if a filament in solution approaches the nanostructures under an angle of less than $55^{\circ}$, the attraction between the filament and the nanostructures is high enough to twist it and it will consequently adsorb along the nanostructures. In contrast, filaments approaching the nanostructures with angles larger than $55^{\circ}$ will simply feel the nanostructures as a general roughness of the sample. On neat $\mathrm{Si}$ the filaments are again forming a similar neuronal network, as can been seen in Fig. 9c. The intersection points are however smaller and single filaments spread over the neat $\mathrm{Si}$ in all directions without preferential orientation. The density of adsorbed filaments is higher on neat $\mathrm{Si}$ than on the nanostructures. Therefore in contrast to protein $\mathrm{A}$, we find that in addition to a lower adsorption on the nanostructures, F-actin has a tendency to adsorb preferentially along the created nanostructures.

As shown previously [6], we observe similar F-actin adsorption on Ti, which depends furthermore on nanostructure height. Fig. 10a shows the created lines which present two distinct heights. The main lines have a height varying between 3 and $4 \mathrm{~nm}$ and have a FWHM of $40 \mathrm{~nm}$. The secondary lines are 1-2 $\mathrm{nm}$ high with a similar FWHM. This height difference is due to a modification of the tip-sample distance during the scan. The large white spots visible on the figure were produced during the $\mathrm{Ti}$ evaporation, and were already present before the LAO treatment. Fig. $10 \mathrm{~b}$ shows the same nanostructures covered by a 4 $\mathrm{s}$ F-actin adsorption. The main lines are still visible in contrast to the secondary lines, which are covered by a thick layer of F-actin. On neat $\mathrm{Ti}$, the concentration of filaments is lower than on the secondary lines, but higher than on the main lines. Therefore the density of adsorbed proteins depends on the topography height. Furthermore F-actin adsorbs preferentially along the nanostructures being 1-2 $\mathrm{nm}$ high, in contrast to the $3-4 \mathrm{~nm}$ high nanostructures and to the neat $\mathrm{Ti}$ where no preferential orientation of adsorbed filaments is noted.
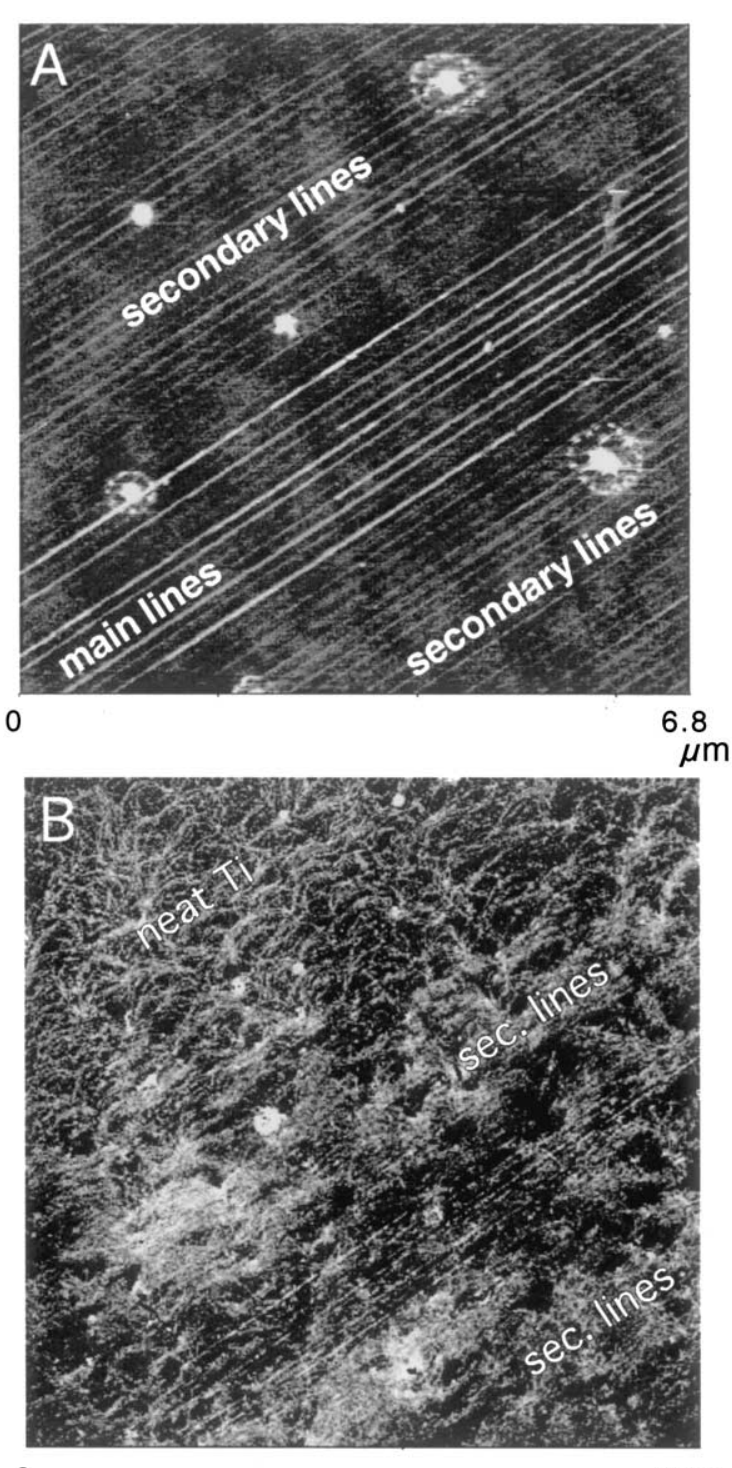

0

17.8

$\mu \mathrm{m}$

Fig. 10. (a) Nanostructures created on Ti. (b) F-actin adsorbed on nanostructured Ti. The vertical scales are $8 \mathrm{~nm}$.

It appears that the nanotopography is an important parameter for the protein adsorption. On $\mathrm{Ti}$ as on $\mathrm{Si}$ an oriented adsorption of F-actin occurs on $1 \mathrm{~nm}$ high parallel lines. Such a topography increases the RMS-roughness up to $0.5 \mathrm{~nm}$, therefore increasing the contact area between the surface and the proteins, favoring the protein adhesion along the lines. On Ti the 3-4 nm high 
nanostructures nevertheless represent an upper cut off, where the adsorbed F-actin density is very low and no preferential orientation of adsorbed proteins is noted. This height, which corresponds to half of the F-actin diameter, seems too rough to favor protein adsorption. Similar height dependencies are observed for cells $[1,2,5]$, where the relevant length scale, however, is of the order of the $\mu \mathrm{m}$.

On Ti the highest density of adsorbed F-actin occurs on $1 \mathrm{~nm}$ high nanostructures, in contrast to $\mathrm{Si}$ where the F-actin adsorption is higher on neat $\mathrm{Si}$ surface. This difference could be explained by the different chemistries and therefore different biocompatibilities of $\mathrm{Si}$ and $\mathrm{Ti}$ towards proteins. For biocompatible surfaces as $\mathrm{Ti}$, the contact area between the adsorbed proteins and the sample surface is maximized, in contrast to non-biocompatible surfaces, as for example $\mathrm{Si}$, where the contact area between the adsorbed proteins and the sample surface is minimized. Furthermore the RMS-roughness of $\mathrm{Ti}$ is already greater for neat surfaces in comparison to $\mathrm{Si}$, so that between the Ti nanostructures the surface is rougher than on Si.

In contrast to F-actin, the protein A shows no preferential adsorption on $1 \mathrm{~nm}$ high nanostructures. Due to their globular shape the contact area on nanostructured or neat $\mathrm{Si}$ remains constant, so that no adsorption difference can be noted. A pattern composed of circular lines of diameter similar to protein A could perhaps locally increase the density of adsorbed protein A.

\section{Conclusion}

The LAO combined with AFM measurements is a very promising technique, which can be applied to study the reaction of biological systems in contact with a defined topography at the $\mathrm{nm}$ scale. XPS measurements have shown that the native oxide thickness is $0.69 \mathrm{~nm}$ for neat $\mathrm{Si}$ and $2.03 \mathrm{~nm}$ on the highest $\mathrm{Si}$ nanostructures. Ti presents a native oxide layer thicker than $2-$ $3 \mathrm{~nm}$, and nanostructures of $1-4 \mathrm{~nm}$ height can be created. Therefore no difference in static surface charge can be considered between the lower and upper parts of the nanostructures. Furthermore the chemistry of the created nanostructures is similar to the native oxide. To date, LAO is the only technique which permits modification of the surface topography in a nanometer range without changing the surface chemistry. We demonstrated that this technique allows us to study the biological activity of adsorbed proteins on nanostructures. Protein A shows no adsorption difference on parallel $1 \mathrm{~nm}$ high nanostructures on Si. The non-specifically bounded IgG also shows no preferential adsorption on or outer the nanostructures covered with protein A. In contrast, the F-actin adsorbs preferentially along $1 \mathrm{~nm}$ high lines on Si. Furthermore the density of protein adsorbed on neat $\mathrm{Si}$ is higher than on nanostructures. On neat $\mathrm{Ti}$ nanostructures of different heights have been created. The F-actin adsorption is the highest on the 1-2 nm high lines with a defined orientation along the lines, in contrast to a low and nonoriented protein adsorption on the $3-4 \mathrm{~nm}$ high nanostructures. In order to approach the in vivo conditions, further experiments have to be performed under aqueous conditions and in solutions where different proteins are present.

In short we have demonstrated that protein can "sense" the nanotopography similarly to the cells at micrometer scales. The topography is therefore an important parameter, which has to be taken into account in the general biomaterial field because the structure of the surface at a nanometer scale can influence the response of biological materials.

\section{Acknowledgements}

We gratefully acknowledge the Dr. H.C. Robert Mathys Stiftung (RMS) Foundation for the financial support provided. We also thank R. Held from the ETH Zürich, Switzerland, for the Ti evaporation. Finally, we appreciated the very fruitful discussions we had with Dr. M. Wymann. 


\section{References}

[1] P. Clark, P. Connolly, A.S.G. Curtis, J.A.T. Dow, C.D.W. Wilkinson, Topographica control of cell behaviour II. Multiple grooved substrata, Development 108 (1990) 635-644.

[2] P. Clark, P. Connolly, A.S.G. Curtis, J.A.T. Dow, C.D.W. Wilkinson, Cell guidance by ultrafine topography in vitro, J. Cell Sci. 99 (1991) 73-77.

[3] B. Wojciak, J. Crossan, A.S.G. Curtis, C. Wilkinson, J. Mater. Sci.: Mater. Med. 6 (1995) 266-271.

[4] B. Wojciak-Stothard, A. Curtis, W. Monaghan, K. MacDonald, C. Wilkinson, Guidance and activation of murine macrophages by nanometric scale topography, Exp. Cell Res. 223 (1996) 426-435.

[5] A. Curtis, C. Wilkinson, Topographical control of cells, Biomaterials 18 (1997) 1573-1583.

[6] C. Galli, M. Collaud Coen, R. Hauert, V.L. Katanaev, M.P. Wymann, P. Gröning, L. Schlapbach, Protein adsorption on topographically nanostructured titanium, Surf. Sci. 474 (2001) L180-L184.

[7] Brookhaven Database of Proteins.

[8] J.J. Langone, Protein A of Staphylococcus aureus and related immunoglobulin receptors produced by streptococci and pneumonococci, Adv. Immunol. 32 (1982) 157252.

[9] A. Müller, E. Diemann, A. Banding, M. Richter, J. Frey, W. Engelhardt, Comment on the imaging of immunoglobulin $\mathrm{G}$ by scanning tunneling microscopy, J. Vac. Sci. Technol. B 11 (2) (1993) 337-338.

[10] T.D. Pollard, J.A. Rooper, Actin and actin-binding proteins, a critical evaluation of mechanisms and functions, Annu. Rev. Biochem. 55 (1986) 987-1035.

[11] J.M. Corbett, C.H. Wheeler, M.J. Dunn, Moelectrophoreses of cardiac tissue from human, dog, rat and mouse: towards the establishment of an integrated two-dimensional protein database, Electrophoresis 16 (1995) 1524-1529.

[12] J.K. Pardee, J.A. Spudich, Purification of muscle actin, Methods Enzymol. 85 (1982) 164-181.

[13] V.L. Katanaev, M.P. Wymann, Microquantification of cellular and in vitro F-actin by rhodamine phalloidin fluorescence enhancement, Anal. Biochem. 264 (1998) $185-190$.

[14] D.F. Williams, Titanium as a metal for implantation: Part1: physical properties, J. Med. Eg. Technol. 1 (4) (1977) 195-198.

[15] H. Zitter, H.J. Plenk, The electrochemical behavior of metallic implant materials as an indicator of their biocompatibility, J. Biomed. Mater. Res. 21 (7) (1987) $881-$ 896.

[16] A. Ikai, STM and AFM of bio/organic molecules and structures, Surf. Sci. Rep. 26 (1996) 261-332.

[17] A. Ishizaka, S. Iwata, Y. Kamigaki, $\mathrm{Si}-\mathrm{SiO}_{2}$ interface characterization by ESCA, Surf. Sci. 84 (1979) 355-374.

[18] V.I. Nefedov, N.P. Sergushin, I.M. Band, M.B. Trzhaskovskaya, Relative intensities in X-ray photoelec- tron spectra, J. Electron Spectrosc. Related Phenomena 2 (1973) 383-403.

[19] J.H. Scofield, Hatree/slater subshell photoionization cross-section at 1254 and $1487 \mathrm{eV}$, J.Electron Spectrosc. Related Phenomena 8 (1976) 129-137.

[20] B.S. Becker, J.A. Golovchenko, B.S. Swartzentruber, Atomic-scale surface modifications using a tunneling microscope, Nature 352 (1987) 419.

[21] J.A. Dagata, J. Schneir, H.H. Harary, C.J. Evans, Modification of hydrogen-passivated silicon by a scanning tunneling microscope operating in air, Appl. Phys. Lett. 56 (1990) 2001.

[22] R.S. Becker, J.A. Golovchenko, B.S. Swartzentruber, Atomic-scale surface modifications using a tunneling microscope, Nature 325 (1987) 419.

[23] R. Held, T. Heinzel, P. Studerus, K. Ensslin, Nanolithography by local anodic oxidation of metal films using an atomic force microscope, Physica E 2 (1998) 748-752.

[24] H. Sugimura, T. Uchida, N. Kitamura, H. Masuhara, Tip-induced anodization of titanium surfaces by scanning tunneling microscopy: A humidity effect on nanolithography, Appl. Phys. Lett. 63 (9) (1993) 1288-1290.

[25] C.R.K. Marrian, E.S. Snow, Proximal probe lithography and surface modification, Microelectronic Eng. 32 (1996) $173-189$.

[26] F. Pérez-Murano, G. Abdal, N. Barniol, X. Aymerich, J. Servat, P. Gorostiza, F. Sanz, Nanometer-scale oxidation of Si (100) surfaces by tapping mode atomic force microscopy, J. Appl. Phys. 78 (11) (1995) 6797-6801.

[27] M. Wendel, B. Irmer, J. Cortes, R. Kaiser, H. Lorenz, J.P. Kotthaus, A. Lorke, Nanolithography with an atomic force microscope, Superlattices Microstructures 20 (3) (1996) 349-356.

[28] F. Bozso, P. Avouris, Thermal and photochemical oxidation of $\mathrm{Si}(111)$ : doping effect and the reaction mechanism, Phys. Rev. B 44 (1991) 9129-9131.

[29] B. Kasemo, J. Lausmaa, Surface science aspects on inorganic biomaterials, CRC Crit. Rev. Biocompatibility 2 (4) (1986) 335-380.

[30] B. Gasser, Reintitan und Varianten seiner Oberflaeche in der Implantologie, Master's thesis, University of Fribourg, Switzerland, dissertation Nr. 1204, 1998.

[31] M.T. Sieger, D.A. Luh, T. Miller, T.-C. Chiang, Photoemission extended fine structure study of the $\mathrm{SiO}_{2} / \mathrm{Si}(111)$ interface, Phys. Rev. Lett. 77 (13) (1996) 2758-2761.

[32] M. Morita, T. Ohmi, E. Hasegawa, M. Kawakami, M. Ohwada, Growth of native oxide on a silicon surface, J. Appl. Phys. 68 (3) (1990) 1272-1281.

[33] H. Watanabe, K. Fujita, M. Ichikawa, Atomic-step observation at buried $\mathrm{SiO}_{2} / \mathrm{Si}(111)$ interfaces by scanning reflection electron microscopy, Surf. Sci. 385 (1997) L952-L957.

[34] M. Collaud Coen, C. Galli, M. Bielmann, R. Lehmann, P. Gröning, L. Schlapbach, Imaging adsorption of proteins on chemically and topographically modified sur- 
faces by SPM, Langmuir (2001) submitted for publication.

[35] M. Collaud Coen, R. Lehmann, P. Gröning, M. Biel- mann, C. Galli, L. Schlapbach, Adsorption and bioactivity of protein A on silicon surfaces studied by AFM and XPS, J. Colloid Interface Sci. 233 (2001) 180-189. 